\title{
Homens agressores de mulheres: uma revisão sistemática de literatura
}

\author{
Men aggressors of women: a systematic literature review
}

Hombres que atacan a mujeres: una revisión sistemática de la literatura

Fernanda Bandeira da Silva ${ }^{1 \star}$, Camila Natália Santos de Sousa ${ }^{1}$, Edilmara Patrícia Rocha ${ }^{1}$, Antonio Junior Amorim dos Santos ${ }^{1}$, Eliane Fraga da Silveira ${ }^{1}$, Dóris Cristina Gedrat ${ }^{1}$.

\section{RESUMO}

Objetivo: Descrever e revisar informações sobre o homem autor de violência contra mulheres, no âmbito das relações intimas, em artigos encontrados nos sites indexadores BVS e SciELO. Métodos: A pesquisa foi tipificada como transversal descritiva e quantitativa. Os descritores utilizados foram "homem" e "agressor". Os critérios de inclusão foram: artigos publicados entre 2015-2019, escritos em língua portuguesa com cunho descritivos/exploratórios transversais e quantitativos ou quanti-qualitativos. O critério de exclusão foi: não abordar o tema da violência entre parceiros íntimos - um homem e uma mulher. As informações buscadas foram: faixa etária, cor/etnia, escolaridade, tipo de agressão praticada, relação com a vítima, causa da agressão, influência de drogas ou álcool e trabalho e renda. A pesquisa foi realizada em dezembro de 2019. Resultados: Com os descritores empregados, os artigos recuperados não apresentaram todas as informações buscadas. Somente o tipo de agressão e relação com a vítima foram informações encontradas na maioria dos artigos, o que demonstra que a partir dos descritores utilizados não é possível montar um perfil completo do homem autor de violência contra a mulher. Considerações finais: A partir das informações coletadas nos artigos recuperados, descrevem frequentemente o perfil do homem agressor de mulheres como esposo praticante de violência física.

Palavras-chave: Violência doméstica, Mulher, Homem.

\begin{abstract}
Objective: Describe and review information about the man who committed violence against women, in the context of intimate relationships, in articles found on the VHL and SciELO indexing sites. Methods: The research was characterized as cross-sectional, descriptive, and quantitative. The descriptors used were "man" and "aggressor". Inclusion criterion were: articles published between 2015 and 2019, documents in Portuguese and transversal and quantitative or quantitative-qualitative descriptors / explorers. The exclusion criterion was: not to talk about violence between intimate partners - a man and a woman. The information sought were: age group, color/ethnicity, education, type of aggression practiced, relationship with victim, cause of aggression, influence of drugs or alcohol and work and income. The survey was conducted in December 2019.Results:With the descriptors used, the retrieved articles did not present all the information sought. Only the type of aggression and relationship with the victim were the most found information, which demonstrates that, based on the descriptors used, it is not possible to build a complete profile of the man who committed violence against women. Final consideration: From the information collected in the retrieved articles, that describe the profile of men who attack women, as spouses who practice physical violence.
\end{abstract}

Key words: Domestic violence, Woman, Man.

1Universidade Luterana do Brasil (ULBRA), Canoas - RS. *E-mail: fernadily@hotmail.com

SUBMETIDO EM: 4/2020

ACEITO EM: 5/2020

PUBLICADO EM: 7/2020

REAS/EJCH | Vol.Sup.n.53 | e3481 | DOI: https://doi.org/10.25248/reas.e3481.2020 Página 1 de 8 


\section{RESUMEN}

Objetivo: Describir y revisar información sobre el hombre que cometió violencia contra la mujer, en el contexto de relaciones íntimas, en artículos encontrados en los sitios de indexación de BVS y SciELO. Métodos: La investigación se caracterizó como transversal, descriptiva y cuantitativa. Los descriptores utilizados fueron "hombre" y "agresor". Los criterios de inclusión fueron: artículos publicados entre 2015-2019, escritos en portugués y descriptivos/exploratorios transversales y cuantitativos o cuantitativos. El criterio de exclusión era: no hablar sobre la violencia entre parejas íntimas, un hombre y una mujer. La información buscada fue: rango de edad, color/etnia, educación, tipo de agresión practicada, relación con la víctima, causa de la agresión, influencia de drogas o alcohol y trabajo e ingresos. La encuesta se realizó en diciembre de 2019. Resultados: Con los descriptores utilizados, los artículos recuperados no presentaron toda la información buscada. Solo se encontró el tipo de agresión y la relación con la víctima en la mayoría de los artículos, lo que demuestra que, según los descriptores utilizados, no es posible construir un perfil completo del hombre que cometió violencia contra la mujer. Consideraciones finales: La información recopilada, describen el perfil de los hombres que atacan a las mujeres como cónyuges que practican la violencia física.

Palabras clave: Violencia doméstica, Mujer, Hombre.

\section{INTRODUÇÃO}

No Brasil, a violência contra a mulher engloba todo ato de brutalidade física, moral, psicológica, patrimonial e sexual praticada em diversas circunstâncias e em qualquer espaço, seja no âmbito do lar e familiar ou em ambientes de entretenimento, culto religioso e espaços de trabalho, aplicando-se a qualquer faixa etária conforme disposto na Lei no 11.340 (BRASIL, 2006), a qual visa abordar as diversas e distintas condições vivenciadas por mulheres em situação de violência.

A Lei no 13.104 (BRASIL, 2015) vem assegurar à mulher a tipificação legal de vítima, em crimes contra pessoa e contra a vida, denominado de feminicídio, evidenciando a situação do crime pela condição de ser mulher. Nessa esteira, esta obra tem como tema a violência contra mulher, com uma delimitação de tema com foco nos seus agentes causadores do sexo masculino. Dentro desse contexto, estabeleceu-se a questão norteadora: qual é o perfil do homem autor de violência contra mulheres?

A relevância do tema está no fato de que no Brasil, apesar de avanços no campo da pesquisa e do debate e das políticas públicas, intervenções direcionadas especificamente aos agressores de mulheres não recebe a devida atenção institucional, assim como da sociedade e da academia (LIMA DC, et al., 2008).

Entender quem é o autor de violência contra mulheres torna-se relevante para que as políticas públicas e a atuação de profissionais da área da saúde, segurança pública e assistência social promovam a prevenção desse tipo de crime e a assistência às vítimas, com o aprimoramento da rede especializada de cuidados e de atendimento, já que pesquisas sobre agressores fornecem novos elementos aos estudos, a partir dos eventos de violência, vítimas e agressores, já existentes (VASCONCELOS MS, et al., 2016; MADUREIRA AB, et al., 2014).

O ideário terminológico sobre "violência contra a mulher" emergiu na década de 1970 a partir dos movimentos feministas e descreve crimes realizados pelo simples fato de seu pertencimento ao gênero feminino. Geralmente, está associada a construções narrativas que tangem a mulher como submissa ao homem e a visões patriarcais das relações interpessoais, mas podem independer da interação de gêneros diferentes, assim como envolver diversas causas e conflitos (RODRIGUES R e JOFFER S, 2015; BRASIL, 2017; MADUREIRA AB, et al., 2014).

O Brasil apresenta atualmente uma rigorosa legislação que visa coibir a violência contra as mulheres, buscando respeitar e assegurar os direitos destas. De acordo com o Mapa de Violência contra a Mulher de 2018 (BRASIL, 2018) a maioria das mulheres vitimizadas pela violência no Brasil tem idade entre 18 e 59 anos, o que corresponde a $83,7 \%$ vítimas e nos 11 meses correntes do ano da pesquisa, houve notificação por parte da imprensa brasileira de 14.796 casos de violência doméstica, sendo que em sua maioria, $58 \%$ 
dos casos de agressão, os atos praticados são por companheiros (namorados, ex, esposos), além de $42 \%$ corresponder aos atos de violência praticados por pessoas que possuam grau de parentesco ou proximidade, como, pais, avôs, tios e padrastos.

No Brasil, a Lei Maria da Penha, de 2006, tornou-se um marco no enfrentamento da violência praticada no ambiente doméstico e no seio familiar (BRASIL, 2006), buscando dar visibilidade às vulnerabilidades vivenciadas por mulheres. Apesar de no país existirem campanhas ao longo do ano que busquem evidenciar a prática da violência, vê-se um número cada vez maior sobre essa problemática. Algo que permite evidenciar e talvez, se debruçar sobre o tema de forma coerente e conforme previsto nas leis de proteção, é o fato das mulheres conseguirem ter acesso às informações, bem como, aos meios físicos para denunciar, como as delegacias especializadas e a rede de proteção psicossocial.

O contraditório é que mesmo com esse aparato legal, os dados sobre feminicídio são alarmantes. De acordo com o Atlas da Violência (IPEA, 2019) 28,5\% dos homicídios cometidos contra as mulheres ocorrem dentro das suas moradias e, ressalta-se que devido a uma subnotificação do local onde os incidentes ocorreram podem elevar o número, chegando $39,3 \%$ que podem decorrer de violência doméstica. $O$ estudo ainda aponta que no Brasil houve uma crescente entre os anos de 2007 e 2017 (de 3,9\% para 4,7\% por 100 mil habitantes) na taxa de homicídios de mulheres, destacando a taxa de homicídios de mulheres negras.

Diante desse cenário nacional, o objetivo desta pesquisa foi descrever e revisar informações sobre o homem autor de violência contra mulheres, no âmbito das relações intimas, presentes nos artigos relacionados ao tema, encontrados no Portal Regional da Biblioteca Virtual em Saúde (BVS) e Scientific Electronic Library Online (SciELO) a partir dos descritores "homem" e "agressor".

\section{MÉTODOS}

Esta pesquisa sistemática de literatura, que resultou neste artigo, foi tipificada como transversal descritiva e quantitativa. As plataformas indexadoras utilizadas para resgatar as obras que foram selecionadas para consulta foram o BVS e SciELO.

Os critérios de inclusão foram: serem artigos científicos publicados entre 2015 e 2019, estarem escritos em língua portuguesa, serem descritivos/exploratórios transversais e quantitativos ou quanti-qualitativos. $\mathrm{O}$ critério de exclusão foram artigos que não falem de violência entre parceiros íntimos, sendo um homem e uma mulher. Os descritores utilizados à pesquisa eletrônica nas plataformas indexadoras foram as palavras: homem e agressor.

As informações buscadas nos artigos, sobre o perfil do homem, autor de violência contra mulher no âmbito doméstico, foram: faixa etária, cor/etnia, escolaridade, tipo de agressão praticada, relação com a vítima, causa da agressão, influência de drogas ou álcool no ato da agressão, trabalho e renda. A pesquisa sistemática de literatura, nas plataformas citadas, foi realizada no mês de dezembro de 2019.

\section{RESULTADOS E DISCUSSÃO}

A pesquisa inicial, somente com os descritores delimitados, remeteu a 351 resultados no Portal Regional BVS, e 15 na SciELO. Com a aplicação dos critérios de inclusão de artigos científicos publicados apenas em língua portuguesa entre 2015-2019, o número diminuiu para 81 obras, no Portal Regional BVSe para 5, na SCIELO.

Na SciELO, com a repetição de uma obra nos resultados da pesquisa, a de Nóbrega VKM, et al. (2019), o número de obras recuperadas caiu para 4. Com a aplicação do critério de exclusão "artigos que não falem de violência entre parceiros íntimos, sendo um homem e uma mulher", Platt VB, et al. (2018), que trata de agressão de crianças, que inclusive também se repete na pesquisa, restaram 2 obras, sendo-as: Nóbrega VKM, et al. (2019) e Stenzel GQL e Lisboa CSM (2017). Mas ambas foram excluídas, devido a sua abordagem qualitativa, que analisou impressões psicossociais relativas ao casamento com homens agressores, não demonstrando informações sobre o perfil dos mesmos, logo, na SciELO, descartou-se a possibilidade de uso dos artigos encontrados. 
Na BVS, de 81 artigos recuperados, após a aplicação do critério de exclusão, citado anteriormente, ficaram Bozzo ACB, et al. (2017), Mendes ZR, et al. (2017), Oliveira LAS e Leal SMC (2016), Dourado SM e Noronha CV (2015), Moreira GAR, et al. (2015) e Costa CTS (2015).

No total, a pesquisa sistemática de literatura resultou em 6 artigos que continham dados que possibilitaram a compreensão do perfil dos homens autores de violência contra mulher, no âmbito das relações íntimas, segundo a literatura científica de 2015-2019 encontrada, prioritariamente, no Portal Regional da Biblioteca Virtual em Saúde. A seguir, os quadros apresentam as informações encontradas em cada artigo recuperado para análise.

Quanto à categorização dos dados sobre as características do "homem agressor", foram utilizados os seguintes critérios: 1 - Dados Socioeconômicos, contendo informações como: Idade, Escolaridade; Cor/Etnia; Renda; Trabalho; e 2 - Dados Característicos da Violência, contendo elementos como: Tipo de Violência; Relação com a vítima; Local da agressão; Antecedentes Criminais; Sob o uso de substâncias químicas no Ato; Alcoolizado no Ato; Causa/Agressão (Quadro 1 e Quadro 2).

Quadro 1 - Informações contendo os dados socioeconômicos encontrados sobre agressores de mulheres no âmbito das relações íntimas.

\begin{tabular}{|c|cccccc|}
\hline \multirow{2}{*}{$\begin{array}{c}\text { Características } \\
\text { socioeconômicas }\end{array}$} & $\begin{array}{c}\text { Bozzo ACB, } \\
\text { et al. (2017) }\end{array}$ & $\begin{array}{c}\text { Mendes ZR, } \\
\text { et al. (2017) }\end{array}$ & $\begin{array}{c}\text { Oliveira LAS e } \\
\text { Leal SMC (2016) }\end{array}$ & $\begin{array}{c}\text { Dourado SM e } \\
\text { Noronha CV (2015) }\end{array}$ & $\begin{array}{c}\text { Moreira GAR, } \\
\text { et al. (2015) }\end{array}$ & $\begin{array}{c}\text { Costa } \\
\text { CTS, et al. } \\
(2015)\end{array}$ \\
\hline Idade & Não informa & Não informa & Não informa & Não informa & Não informa & $\begin{array}{c}\text { Não } \\
\text { informa }\end{array}$ \\
\hline Escolaridade & Não informa & Não informa & Não informa & Não informa & Não informa & $\begin{array}{c}\text { Não } \\
\text { informa }\end{array}$ \\
\hline Cor/Etnia & Não informa & Não informa & Não informa & Não informa & Não informa & $\begin{array}{c}\text { Não } \\
\text { informa }\end{array}$ \\
\hline Renda & Não informa & Não informa & Não informa & Não informa & Não informa & $\begin{array}{c}\text { Não } \\
\text { informa }\end{array}$ \\
\hline Trabalho & Não informa & Não informa & Não informa & Não informa & Não informa & $\begin{array}{c}\text { Não } \\
\text { informa }\end{array}$ \\
\hline
\end{tabular}

Fonte: Silva FB, et al., 2020.

Segundo a pesquisa realizada, é possível apreciar que os artigos recuperados não contam com informações suficientes para que seja composto um perfil do homem agressor de mulheres a partir dos dados disponibilizados. Em outras palavras é possível dizer que não há possibilidade de montar um perfil de homens autores de agressão contra mulheres no Brasil, a partir da literatura que aborda o tema discutido, pois, há uma relevante falta de informações a respeito do ato da violência em si e também ao que concerne ao autor.

Por fim da aplicação dos critérios de inclusão e exclusão, as obras resgatadas, as de Bozzo ACB, et al., (2017), Mendes ZR, et al. (2017), Oliveira LAS e Leal SMC (2016), Dourado SM e Noronha CV (2015), Moreira GAR, et al., (2015) e Costa CTS, et al., (2015) foram analisadas e nenhuma das mesmas apresentava todas as informações buscadas: idade, escolaridade, cor/etnia, renda, trabalho.

Souza DF e Nery IS (2014), realizaram uma pesquisa a partir da análise de dados coletados no Juizado de Violência Doméstica e Familiar Contra a Mulher da Comarca de Teresina-PI. Com relação às características dos agressores, é possível identificar que as faixas etárias são diversas, sendo entre 29 a 39 anos a que mais prevalece. Além disso, sobre a condição de relação com a vítima, 48,34\% são casados ou possuem união estável, enquanto $40,76 \%$ se diziam solteiros. Os números referentes à essa situação conjugal de solteiros, não foi encontrado nas pesquisas contempladas no presente estudo.

Brasileiro AE e Melo MB (2016) desenvolveram um estudo sobre o perfil sócio jurídico de agressores, com base na abordagem quantitativa e qualitativa, sendo os registros arquivados na Delegacia da Mulher de Campina Grande (PB), o seu material de coleta. Nesta pesquisa, foi possível identificar que quanto ao nível de escolaridade dos agressores, 55,8\% possuíam o Ensino Fundamental e que as profissões exercidas em 
grande maioria não exigiam alto nível de instrução. A idade dos agressores em média foi de 35,25 anos, e quanto às motivações que levaram à agressão, o que teve maior destaque foram as discussões, seguidas de uso de bebida, não aceitação da separação, ciúme, dinheiro, uso de drogas, dentre outras questões.

Referente às características gerais da violência, informações como local da agressão antecedentes criminais, se houve consumo de drogas ou bebida alcoólica no ato da agressão, bem como, a causa da agressão não foram identificadas, o que pode ser observado no Quadro 2.

Quadro 2 - Informações contendo os dados referente às características da violência por homens agressores de mulheres no âmbito das relações íntimas.

\begin{tabular}{|c|c|c|c|c|c|c|}
\hline \multirow[b]{2}{*}{$\begin{array}{c}\text { Características da } \\
\text { violência }\end{array}$} & \multicolumn{6}{|c|}{ AUTORES/ARTIGOS } \\
\hline & $\begin{array}{l}\text { Bozzo ACB, } \\
\text { et al. (2017) }\end{array}$ & $\begin{array}{l}\text { Mendes ZR, } \\
\text { et al. (2017) }\end{array}$ & $\begin{array}{c}\text { Oliveira LAS e } \\
\text { Leal SMC (2016) }\end{array}$ & $\begin{array}{c}\text { Dourado SM e } \\
\text { Noronha CV (2015) }\end{array}$ & $\begin{array}{l}\text { Moreira GAR, } \\
\text { et al. (2015) }\end{array}$ & $\begin{array}{c}\text { Costa } \\
\text { CTS, et al. } \\
(2015)\end{array}$ \\
\hline Tipo de violência & Psicológica & Física & Não informa & Física & Física & $\begin{array}{c}\text { Psicológic } \\
\mathrm{a} \\
\end{array}$ \\
\hline $\begin{array}{c}\text { Relação com a } \\
\text { vítima }\end{array}$ & Esposo & Esposo & Esposo & Esposo & Nãoinforma & Esposo \\
\hline $\begin{array}{c}\text { Local da } \\
\text { agressão }\end{array}$ & Não informa & Não informa & Não informa & Não informa & Não informa & $\begin{array}{c}\text { Não } \\
\text { informa }\end{array}$ \\
\hline $\begin{array}{l}\text { Antecedentes } \\
\text { criminais }\end{array}$ & Não informa & Não informa & Não informa & Não informa & Não informa & $\begin{array}{c}\text { Não } \\
\text { informa }\end{array}$ \\
\hline $\begin{array}{c}\text { Sob efeito de } \\
\text { substâncias } \\
\text { químicas no ato }\end{array}$ & Não informa & Não informa & Sim & Não informa & Não informa & $\begin{array}{l}\text { Não } \\
\text { informa }\end{array}$ \\
\hline $\begin{array}{c}\text { Alcoolizado no } \\
\text { ato }\end{array}$ & Não informa & Não informa & Não informa & Não informa & Não & Sim \\
\hline Causa/agressão & Não informa & Não informa & Não informa & Não informa & Não informa & $\begin{array}{c}\text { Não } \\
\text { informa }\end{array}$ \\
\hline
\end{tabular}

Fonte: Silva FB, et al., 2020.

O tipo de violência e relação com a vítima foram as informações mais constatadas, pois, aparecem em 5 (cinco) estudos.Com relação ao tipo de violência, frequentemente foi descrito nas obras a física, cuja aparece em 3 (três)dos trabalhos que abordam o tipo de violência praticado pelo agressor. $O$ tipo de relação com a vítima mais apontado nos artigos analisados foi o que colocava o agressor na condição de esposo, sendo que somente uma obra não traz informações sobre o tipo de relação da vítima com o agressor.

No artigo de Madureira AB, et al. (2014), com pesquisa documental que analisou autos de prisão, de 2005 a 2010, de uma Delegacia Especial da Mulher no Paraná, aborda de forma especifica perfil de agressores de mulheres, mas que não foi resgatado com os descritores empregados na pesquisa que resultou neste artigo, tem-se que a violência física é a mais praticada por agressores de mulheres, o que acompanha os resultados encontrados. Ainda em Madureira AB, et al. (2014), evidenciou-se que a maioria dos agressores de mulheres eram esposos, o que mais uma vez condiz com os resultados da presente pesquisa.

Apesar disso, uma das questões acerca da violência contra a mulher que precisa ser ressaltada é como são notificados os casos, que em grande maioria só vão ao conhecimento das Delegacias Especializadas quando culminam com a agressão física. O que de fato é possível afirmar, vislumbrando já o que a literatura nacional contempla é que a cultura patriarcal e heteronormativa propõe sobre como o homem deve se comportar com relação à sua mulher, inclusive na prática da violência, bem como, sobre o lugar que a mulher ocupa nessas relações.

É muito comum que o comportamento agressivo não seja reconhecido como tal, muitas vezes, é posto ao pensamento do cotidiano que quando (e como) as formas de violência ocorrem, estas, devem ser resolvidas no próprio ambiente familiar. Há, por vezes, ainda no pensamento coletivo o domínio do homem sobre o corpo da mulher e sobre a sua vida, o que pode acrescer o número de casos de violência. 
Da mesma forma, Silva ACLG, et al. (2014), apontou que há prevalência do parceiro íntimo tido como esposo, como maior agressor de mulheres. E Vasconcelos MS, et al. (2016), em um estudo documental com dados de 2008-2012 de 512 fichas de atendimento da Secretaria da Mulher do município de Vitória de Santo Antão, na Zona da Mata Pernambucana, também verificou predominância da violência física praticada, na maior parte dos casos, por esposos.

O consumo de drogas e de álcool, no ato da agressão, foram também informações recorrentes uma vez que informações sobre drogas são citadas uma vez e sobre ingestão de bebida alcoólica é três vezes abordada. Oliveira LAS e Leal SMC (2016) aponta dados sobre uso de drogas pelo agressor, contudo, não especificando a qual. Moreira GAR, et al. (2015) e Costa CTS, et al. (2015) trazem informações sobre o consumo de álcool, no ato da violência contra as parceiras íntimas, sendo que o primeiro aponta que o agressor não havia feito ingestão de tal substância e o segundo, que sim, o praticante da violência havia ingerido bebida alcoólica.

Vasconcelos MS, et al. (2016) apontam, sobre o consumo de álcool pelos agressores, que dos casos que analisaram, a maioria tinha consumido álcool, o que condiz com o que foi contato com o achado em Costa CTS, et al. (2015). Assim como Oliveira LAS e Leal SMC (2016), autor recuperado pela pesquisa que deu origem a este artigo, Vasconcelos MS, et al. (2016) aponta que os agressores, em sua maioria, também fizeram uso de drogas.

Em um estudo qualitativo desenvolvido por Stenzel GQL (2019) com três participantes, descreve características como a faixa etária entre 45 e 63 anos, detidos em um presídio em função de assassinato e violência física, cor branca, com escolaridade entre $1^{\circ}$ grau completo e Superior Incompleto. A autora refere a escassez de materiais que possam auxiliar a traçar um perfil, mas, apresenta algumas informações que foram comuns entre esses homens, como o caso de violência ou negligência vivenciadas pelos agressores enquanto infância e que nenhum destes havia sido detido anteriormente ao crime cometido.

Scott JB e Oliveira IF (2018) realizaram uma pesquisa qualitativa de base documental junto às fichas (241 no total) de atendimento de um núcleo da região nordeste do Brasil, reconhecida pelos seus altos índices de violência contra a mulher, contemplando o período de setembro de 2012 a setembro de 2017. Neste estudo foi possível identificar que a faixa etária comum esteve entre 31 e 40 anos de idade, sendo homens brancos, em união estável, com baixa escolaridade.

O Quadro 3 busca demonstrar as principais características dos artigos que foram classificados dentro dos critérios do presente estudo. Informações como tipo da pesquisa, local, período do estudo e amostragem podem ser contempladas.

Quadro 3 - Principais características dos artigos recuperados.

\begin{tabular}{|c|c|c|c|c|c|c|}
\hline \multirow[b]{2}{*}{$\begin{array}{c}\text { Características da } \\
\text { pesquisa }\end{array}$} & \multicolumn{6}{|c|}{ AUTORES } \\
\hline & $\begin{array}{l}\text { Bozzo ACB, } \\
\text { et al. (2017) }\end{array}$ & $\begin{array}{l}\text { Mendes ZR, } \\
\text { et al. (2017) }\end{array}$ & $\begin{array}{c}\text { Oliveira LAS e } \\
\text { Leal SMC (2016) }\end{array}$ & $\begin{array}{c}\text { Dourado SM e } \\
\text { Noronha CV (2015) }\end{array}$ & $\begin{array}{l}\text { Moreira GAR, } \\
\text { et al. (2015) }\end{array}$ & $\begin{array}{l}\text { Costa } \\
\text { CTS, et } \\
\text { al. }(2015)\end{array}$ \\
\hline Tipo & Quantitativo & Quantitativo & Quantitativo & Quantitativo & Quanti-Quali & $\begin{array}{c}\text { Quantitati } \\
\text { vo }\end{array}$ \\
\hline Local & $\begin{array}{l}\text { Ribeirão } \\
\text { Preto/SP }\end{array}$ & $\begin{array}{c}\text { São } \\
\text { Francisco do } \\
\text { Conde/BA }\end{array}$ & Parobé/RS & Salvador/BA & Brasil & Sobral/CE \\
\hline Período & $\begin{array}{l}\text { De 2009- } \\
2013\end{array}$ & $\begin{array}{l}\text { De 2012- } \\
2014\end{array}$ & De 2013-2015 & De 2004-2008 & $\begin{array}{l}\text { De 2009- } \\
2013\end{array}$ & $\begin{array}{l}\text { Ano de } \\
2009\end{array}$ \\
\hline $\begin{array}{l}\text { Amostragem em } \\
\text { cada estudo }\end{array}$ & 1.504 casos & 67 boletins & $\begin{array}{l}133 \text { fichas de } \\
\text { atendimento }\end{array}$ & 164 boletins & 21.871 casos & $\begin{array}{c}1.546 \\
\text { boletins }\end{array}$ \\
\hline
\end{tabular}

Fonte: Silva FB, et al., 2020. 
Somente Moreira GAR, et al. (2015) apresentaram uma metodologia quanti-quali. Os demais autores realizaram pesquisas quantitativas. Uma das pesquisas, a de Bozzo ACB, et al. (2017), foi realizada na região Sudeste do Brasil, mais exatamente no Estado de São Paulo, em Ribeirão Preto. Na região Sul, há o trabalho de Oliveira LAS e Leal SMC (2016), em Parobé, RS. O Nordeste é a região com mais pesquisas resgatadas, com um total de 3 (três), sendo Dourado SM e Noronha CV (2015), realizada em Salvador, BA, a de Mendes et al. (2017), também na Bahia, em São Francisco do Conde, e Costa CTS, et al. (2015), em Sobral, no Ceara. Moreira GAR, et al. (2015) foram os únicos autores que fizeram uma pesquisa de cunho nacional (Quadro 3).

Os maiores recortes temporais dos dados recolhidos pelas pesquisas foram de 4 (quatro) anos, nas obras de Bozzo ACB, et al. (2017) e Moreira GAR, et al. (2015), ambos de 2009 a 2013, e Dourado SM e Noronha CV (2015), de 2004 a 2008. O menor período de tempo analisado foi o da pesquisa de Costa CTS, et al. (2015), apenas 1 (um) ano, o de 2009. A maior amostragem foi a de Moreira GAR, et al. (2015), com 21.871 casos em seguida aparece Costa CTS, et al. (2015), que analisou 1.546 boletins policiais. Conseguinte há Bozzo ACB, et al. (2017), com 1.504 casos, Dourado SM e Noronha CV (2015), que trabalharam com 164 boletins, e, por fim, com a menor amostra, Mendes ZR, et al. (2017), com 67 boletins. Os artigos recuperados foram publicados nos anos 2015, 2016 e 2017.

Dada a verificação do tema violência contra mulheres, em um ambiente específico, Oliveira LAS e Leal SMC (2016) foram os únicos autores a não utilizarem dados de Boletins Policiais das Delegacias de Atendimento Especial à Mulher e do Sistema de Informação de Agravos de Notificação (SINAN). Os Boletins da Delegacia de Atendimento Especial à Mulher foras as fontes de dados mais consultadas, dentro as pesquisas, aparecendo em 3 (três) trabalhos. Em seguida, estão as notificações do SINAN.

Bozzo ACB, et al. (2017), Mendes ZR, et al. (2017) e Oliveira LAS e Leal SMC (2016) tiveram como objetivos de suas pesquisas, descrever o perfil da mulher vítima de violência. Dourado SM e Noronha CV (2015) verificaram os danos ao rosto de mulheres, causados por seus parceiros íntimos. Moreira GAR, et al. (2015) analisou o quadro de violência sexual contra a mulher no Brasil e Costa CTS, et al. (2015) examinaram contextos e fatos envolvidos nos B.O. de ocorrências de mulheres vítimas de violência.

Cabe apontar que a análise das obras revelou, para além das informações buscadas (Quadro 1 e 2), excessivas informações sobre as vítimas, que não são citadas nesta obra, já que o intuito da pesquisa que a originou estava na busca de informações sobre os agressores de violência contra mulheres. Contudo, não se referindo à vítima como um ator menos importante, é imprescindível revelar a crítica, quanto a essa constatação, de que é preciso, na literatura e, principalmente, nas fontes consultadas pelos autores (Quadro 3), que sejam apontados mais dados e informações sobre os autores das agressões, o que poderia contribuir de forma mais significativa com campanhas e políticas públicas de prevenção e coibição desse tipo de violência.

O excesso de atenção à perspectiva da mulher que é vítima de violência, praticada por homens, no âmbito das relações íntimas, também é algo destacado por Silva ACLG, et al. (2014), que em sua revisão sistemática de literatura a respeito do perfil desses agressores, aponta na literatura uma forte tendência de estudos com vítimas, o que, para os autores, é uma limitação e abre lacunas sobre a compreensão dos agressores.

Silva ACLG, et al. (2014) explica, sobre essa constatação, que a maioria dos estudos que se debruçam sobre tal fenômeno o abordam do ponto de vista conjugal e que buscam informações nas delegacias especializadas em atendimento à mulher. Ademais, a pesquisa limitou-se aos achados ligados aos descritores "homem" e "agressor". Obviamente outras buscas com outros descritores possibilitarão outros resultados. No entanto, esta pesquisa, a que originou este artigo com seus resultantes, lançou mão dos termos empregados com intuito de resgatar artigos que abordassem apenas perfis de homens agressores de mulheres.

Como o consumo de drogas e álcool, no ato da prática da violência contra mulheres, pelos seus agressores, não é algo recorrente nos artigos recuperados, tais informações não constarão na formação de um perfil conclusivo do homem agressor de mulheres, no âmbito íntimo, assim como as informações que foram buscadas, mas não encontradas, também não participarão de tal conclusão. Somente tipo de violência e relação do agressor com a vítima é que comporão tal descrição. 


\section{CONSIDERAÇÕES FINAIS}

Com base na literatura pesquisada, é possível afirmar que os resultados aqui alcançados são parciais, visto que os homens agressores apenas são descritos na qualidade de 'esposos' que praticaram violência física contra suas companheiras e/ou cônjuges. Por falta de informações nas obras coletadas, não é possível descrever ou mesmo comparar a etnia/cor do sujeito agressor, bem como, idade, escolaridade, renda, trabalho, local da agressão, antecedentes criminais, se drogado ou alcoolizado no ato da violência e os motivos que culminaram na agressão. Algo que se destacou nos achados é o tipo de violência que foi descrita de modo frequente - a física, seguida da psicológica. Muitas informações sobre o perfil psicossocial e/ou demográfico foram encontradas em pesquisas de cunho qualitativo, documental, em anos anteriores ao que a presente pesquisa fez o recorte.

\section{REFERÊNCIAS}

1. BOZZO ACB, et al. Violência doméstica contra a mulher: caracterização dos casos notificados em um município do interior paulista. Revista de Enfermagem da UERJ, [s.I.], 2017, 25: 5.

2. BRASIL. Decreto-Lei 2.848, de 07 de dezembro de 1940. Código Penal. Diário Oficial da União, Rio de Janeiro, 31 dez. 1940.

3. Lei no 13.104, de 9 de março de 2015. Lei do Feminicídio. Brasília. DF: Câmara dos Deputados, Edições Câmara, 2014.

4. Lei n. 11.340 de 7 de agosto de 2006. Lei Maria da Penha. Brasília. DF: Câmara dos Deputados, Edições Câmara, 2006.

5. _. Mapa da Violência Contra a Mulher 2018. Brasília. DF: Câmara dos Deputados. 55ª Legislatura - 4ª sessão legislativa.

6. BRASILEIRO E, MELO MB. Agressores na violência doméstica: um estudo do perfil sóciojurídico. Revista de Gênero, Sexualidade e Direito. Curitiba, 2016; 2(2): 189- 208.

7. COSTA CTS, et al. Violência contra a mulher: fatos e contextos de boletins de ocorrências. Revista de Enfermagem UFPE online, [s.I.], 2015, 9(1): 288-295.

8. DOURADO SM, NORONHA CV. Marcas visíveis e invisíveis: danos ao rosto feminino em episódios de violência conjugal. Ciência e Saúde coletiva, [s.I.], 2015, 20(9): 2911-2920.

9. INSTITUTO DE PESQUISA ECONÔMICA APLICADA, FÓRUM BRASILEIRO DE SEGURANÇA PÚBLICA. Atlas da violência 2019. Brasília: Rio de Janeiro: São Paulo: Instituto de Pesquisa Econômica Aplicada; Fórum Brasileiro de Segurança Pública. 2019.

10. LIMA DC, et al. Homens, gênero e violência contra a mulher. Saúde e Sociedade, São Paulo, SP, 2008, $17(2)$ : 69-81.

11. MADUREIRA AB, et al. Perfil de homens autores de violência contra mulheres detidos em flagrante: contribuições para o enfrentamento. Escola Anna Nery, Curitiba, PR, 2014, 18(4): 600-606.

12. MENDES ZR, et al. Mulheres vítimas de violência doméstica: uma abordagem no núcleo da delegacia em atendimento à mulher de um município do Estado da Bahia. Revista Brasileira de Ciência e Saúde, [s.I.], v. 2017, 21(1): 21-28.

13. MOREIRA GAR, et al. Notificações de violência sexual contra a mulher no Brasil. Revista Brasileira de Promoção da Saúde, [s.I.], 2015, 28(3): 327-336.

14. OLIVEIRA LAS, LEAL SMC. Mulheres em situação de violência que buscaram apoio no centro de referência Geny Lehnen/RS. Enfermagem em Foco, Brasília, DF, 2016, 7(2): 78-82.

15. RODRIGUES, R, JOFFER S. Violência contra a mulher: uma expressão da questão social em evidência. In.: Anais do Congresso Internacional de Política Social e Serviço Social: Desafios Contemporâneos, Londrina, PR, 2015, a. 1, 10p.

16. SCOTT J, OLIVEIRA IF. Perfil de Homens Autores de Violência Contra a Mulher: uma análise documental. Revista de Psicologia da IMED [Online], 10.2 (2018): 71-88. Web. 22 Mai. 2020

17. SILVA ACLG, et al. O que se sabe sobre o homem autor de violência contra a parceira íntima: uma revisão sistemática. Revista Panamericana de Salud Pública, [s.I.], 35(4): 278-283, 2014.

18. SOUZA DF, NERY IS. Políticas públicas e os agressores das mulheres vítimas de violência doméstica e familiar. Universidade Federal Rural de Pernambuco, Recife - PE. 18 REDOR. 24 a 27 de novembro de 2014.

19. STENZEL GQL. Características de personalidade de agressores conjugais: um estudo qualitativo. Pensando fam., Porto Alegre, 2019; 23(1): 137-152.

20. VASCONCELOS MS, et al. Perfil do agressor e fatores associados à violência contra mulheres. Cogitare Enfermagem, Recife, PE, 2016, 21(1): 01-10. 